\title{
Validação de um sistema de previsão para a mancha bacteriana do tomateiro
}

\author{
Leandro Luiz Marcuzzo ${ }^{1}$, Walter Ferreira Becker², José Mauricio Cunha Fernandes ${ }^{3}$
}

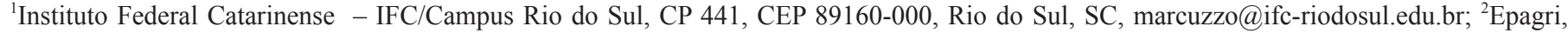
Estação Experimental de Caçador, CP 591, CEP 89163-356, Caçador, SC, wbecker@epagri.sc.gov.br; ${ }^{3}$ Embrapa Trigo, Rodovia BR 285, km 174, CP 451, Passo Fundo, RS,

Autor para correspondência: Leandro Luiz Marcuzzo (marcuzzo@ifc-riodosul.edu.br)

Data de chegada: 19/03/2013. Aceito para publicação em: 16/01/2015.
\end{abstract}

$10.1590 / 0100-5405 / 1918$

\section{RESUMO}

Marcuzzo, L.L.; Becker, W.F.; Fernandes, J.M.C. Validação de um sistema de previsão para a mancha bacteriana do tomateiro. Summa Phytopathologica, v.41, n.3, p.214-218, 2015.

Com o objetivo de validar um modelo de previsão, com diferentes níveis de severidade comparados à pulverização convencional no controle da mancha bacteriana do tomateiro, foram conduzidos experimentos em Caçador/SC durante os ciclos de cultivo de 2006/07, 2007/08 e 2009/10. Os regimes de pulverização foram estabelecidos de acordo com a severidade estimada ( $\mathrm{SE}=\%$ de severidade em folhas $/ 100$ ) de 0,05 ; $0,10,0,15$ e 0,25 , baseado no modelo $\mathrm{SE}=0,0001538 *\left\{\left[(x-8)^{2,4855647}\right.\right.$ $\left.*\left((32-x)^{0,7091962}\right)\right\} *\{[0,64289 /(1+21,26122 * \exp (-0,12435 * y)\} \mathrm{e}$ no sistema convencional (pulverizações a cada 5 e 7 dias e duas vezes por semana, dependendo do ciclo de cultivo). Não houve diferença significativa entre os tratamentos quanto à produtividade $\mathrm{e}$ incidência da doença em frutos. $\mathrm{Na}$ área abaixo da curva de progresso da doença (AACPD), constatou-se redução de $25,71 \%$ na SE 0,15 para o mesmo número de pulverizações realizadas semanalmente. Nos ciclos 2007/08 e 2009/10 os tratamentos não diferiram entre si quanto a AACPD, mas no sistema de previsão com SE 0,15 o número de pulverizações foi mais que $50 \%$ menor em relação ao sistema com duas aplicações semanais.

Palavras-chave: Solanum lycopersicum, previsão de doenças, epidemiologia, Xanthomonas spp.

\section{ABSTRACT}

Marcuzzo, L.L.; Becker, W.F.; Fernandes, J.M.C. Validation of a forecast system for tomato bacterial spot. Summa Phytopathologica, v.41, n.3, p.214-218, 2015.

Aiming to validate a forecast model with different severity levels compared to conventional spraying to control tomato bacterial spot, experiments were conducted in Caçador, SC, during the crop seasons 2006/07, 2007/08 and 2009/10. The spraying regimens were established according to the predicted severity $(\mathrm{SP}=$ severity percentage/100) of $0.05,0.10,0.15$ and 0.25 based on the model SP $=0.0001538 *\left\{\left[(x-8)^{2.4855647} *\left((32-x)^{0.7091962}\right)\right\} *\{[0.64289 /\right.$ $(1+21.26122 * \exp (-0.12435 * y)\}$ and the conventional system (spraying at every
5 and 7 days and twice a week, depending on the crop cycle). There was no significant difference between treatments for productivity and disease incidence in fruits. In the area under the disease progress curve (AUDPC), there was a reduction of $25.71 \%$ in SP 0.15 for the same number of weekly applications. In 2007/08 and 2009/10 cycles, treatments did not differ as to AUDPC, but in the forecast system with SP 0.15 the number of sprays was more than $50 \%$ lower, compared to the system with two weekly applications.

Additional keywords: Solanum lycopersicum, plant disease forecaster, epidemiology, Xanthomonas spp.

O cultivo de tomateiro (Solanum lycopersicum) ocupa uma posição de destaque na produção agrícola, pois é explorado intensivamente em todo o território nacional, com uma área cultivada de 1.280.47 hectares, produzindo mais de 1.344.9 toneladas na safra agrícola de 2013. No estado de Santa Catarina abrange uma área de 2.863 hectares e uma produção 187.900 toneladas. Desses valores, $48 \%$ da área plantada está na microrregião de Joaçaba, onde o município de Caçador cultiva 1000 hectares e detém uma produtividade média de 85 ton.ha ${ }^{-1}$, correspondendo a $45 \%$ da produção estadual (25).

Diversas são as doenças que incidem na cultura, e entre elas, as causadas por fitobactérias, caracterizam-se como organismos de difícil controle, pois depende mais do manejo da cultura do que propriamente do controle químico. Muitos dos produtos químicos disponíveis no mercado não apresentam uma efetividade total de controle, principalmente os antibióticos devido à sua baixa absorção e translocação e serem altamente lixiviáveis em condições de umidade (24). Produtos à base de cobre em mistura com mancozeb têm resultado de controle satisfatório no campo (18).

O clima da região de Caçador e do Alto Vale do Rio do peixe conforme a classificação de Köepen é do tipo Cfb (21). Nessas condições, a fitobactéria mais importante na cultura do tomateiro é Xanthomonas campestris pv. vesicatoria (Doige) Dye, agente causal da mancha bacteriana (13). Atualmente essa bactéria também é denominada de Xanthomonas euvesicatoria (9). Outras espécies têm sido associadas à doença como $X$. gardneri em Caçador, SC e no Brasil Central $(4,22)$ e $X$. vesicatoria e X. perforans já citadas em literaturas (12) com mesma sintomatologia. Neste trabalho, será adotada a nomenclatura de Xanthomonas spp. como agente causal da 
mancha bacteriana. A mancha bacteriana do tomateiro é favorecida pela presença de molhamento foliar e temperatura entre 20 e $30{ }^{\circ} \mathrm{C}$ (12) durante a época de safra que se concentra nos meses de setembro até abril (5) ocorrendo em folhas e frutos (14).

Muitas das doenças de plantas têm sido controladas por métodos empíricos com consequente uso desnecessário de agrotóxicos e aumento dos custos de produção, comprometendo a rentabilidade financeira da cultura, além de impactar o meio ambiente e a possibilidade de resíduos no produto oferecido ao consumo da população (24). O desenvolvimento da doença depende da interação entre ambiente, patógeno e hospedeiro. Quanto ao ambiente, a temperatura e o molhamento foliar são fundamentais para o processo epidemiológico, podendo ser determinados através de modelos matemáticos $(2,8,28)$.

Mediante esse contexto, o melhor manejo de controle inclui a previsão de doenças, em que estas são correlacionadas com a variação climática, principalmente durante o processo da infecção (26).

Segundo Bergamim Filho \& Amorim (3), os sistemas de previsão de doenças de plantas são representações simplificadas da realidade e preveem o início ou o desenvolvimento futuro de uma doença (1, 11,23), além da previsão do momento adequado à pulverização com agrotóxicos, considerando que o patógeno encontra-se em quantidades suficientes para iniciar uma epidemia e que o hospedeiro seja suscetível ao ataque (20).

Este trabalho teve como objetivo validar um sistema de previsão para a mancha bacteriana do tomateiro incitada por Xanthomonas spp.

\section{MATERIAL E MÉTODOSO}

A validação do sistema de previsão da mancha bacteriana do tomateiro foi realizada nos ciclos de cultivo de 2006/07, 2007/08 e 2009/10 na Empresa de Pesquisa Agropecuária e Extensão e Rural de Santa Catarina S/A - EPAGRI, Estação Experimental de Caçador, localizada a $26^{\circ} 81^{\prime} 93$ ' S e $51^{\circ} 83^{\prime} 53^{\prime}$ 'W e altitude de $952 \mathrm{~m}$.

Os dados das variáveis meteorológicas, como temperatura, umidade relativa e molhamento foliar, foram obtidos através de um termohigro-umectógrafo (marca G. Lufft, modelo 8341.R3) instalado em abrigo meteorológico oficial, e o índice pluviométrico medido pelo pluviômetro na estação meteorológica da Estação Experimental da Epagri/Caçador, localizada a $500 \mathrm{~m}$ do local do experimento.

Mudas de tomateiro do cultivar Carmem (ciclo 2006/2007 e 2007/2008) e do cultivar Alambra (ciclo 2009/2010) foram produzidas em bandejas contendo substrato Plantmax ${ }^{\circledR}$ no sistema floating e transplantadas a campo após 25 dias. O sistema de condução da cultura foi por tutoramento vertical com uma planta e duas hastes por cova no espaçamento de $1,5 \mathrm{~m}$ x $0,6 \mathrm{~m}$. A calagem, adubação e tratos culturais foram realizados conforme a recomendação para a cultura na região do Alto Vale do Rio do Peixe, SC (5).

O Sistema de Previsão da Mancha Bacteriana a ser validado foi o modelo descrito por Marcuzzo et al. (17) em: $\mathrm{SE}=0,0001538$ * $\left\{\left[(x-8)^{2,4855647 *}\left((32-x)^{0,7091962}\right)\right\} *\{[0,64289 /(1+21,26122 * \exp \right.$ $\left.\left(-0,12435^{*} y\right)\right\}$, em que SE $=$ Severidade estimada $(\%$ de severidade em folhas/100); $x=$ temperatura média diária $\left({ }^{\circ} \mathrm{C}\right) ; y=$ molhamento foliar (h). No ciclo 2006/07 efetuou-se a pulverização com base nos valores de $\mathrm{SE}$ de 0,$05 ; 0,15 ; 0,25$, juntamente avaliado com o sistema convencional de controle por meio de pulverização realizado a cada cinco e sete dias. Com base nos resultados do ciclo 2006/07 os valores de SE para os demais ciclos foram ajustados para, valores de SE de 0,05; 0,$10 ; 0,15$ e o sistema convencional com duas pulverizações semanais comumente realizados pelos produtores da região. No ciclo 2009/2010 avaliou-se os valores de SE 0,10 e 0,15 e o sistema convencional com duas pulverizações semanais. A pulverização, no sistema de previsão, foi realizada quando o somatório diário dos valores de cada SE foi atingida, sendo então zerado este somatório e iniciado nova contagem dos valores de severidade.

Para os tratamentos baseados no sistema de previsão, o primeiro alerta ocorreu após a sétima semana do transplante, com inicio da pulverização. Esta ocorreu três semanas antes da maturação dos frutos do primeiro cacho, conforme estudo epidemiológico (16). Com os sistemas de previsão as pulverizações foram iniciadas somente na oitava semana do transplante, em conformidade com os alertas para início das pulverizações. Por outro lado, as pulverizações seguindo o controle convencional foram sempre iniciadas na semana do transplante. Quando da ocorrência acumulada de precipitações $\geq 25 \mathrm{~mm}$ todos os tratamentos foram pulverizados (sistema de previsão e convencional).

No controle da mancha bacteriana foi utilizada a mistura comercial de oxicloreto de cobre (30\%) mais mancozeb (44\%) (200 g pc.hl $\left.{ }^{-1}\right)$. Para as demais doenças fúngicas foliares da cultura foi utilizado clorothalonil (75\%) (200 g pc.hl $\left.{ }^{-1}\right)$ aplicado semanalmente ou sempre após as precipitações acumularem $25 \mathrm{~mm}$ (incluindo-se as parcelas testemunha). Para o controle de pragas foram empregados deltamethrine $(2,5 \%)\left(40 \mathrm{ml} \mathrm{pc} \cdot \mathrm{hl}^{-1}\right)$ e etofenproxi (10\%) $\left(200 \mathrm{ml} \mathrm{pc} \cdot \mathrm{hl}^{-1}\right)$ aplicados em sucessão a cada semana.

O delineamento experimental conduzido a campo foi em blocos casualizados com cinco tratamentos e seis repetições. Cada parcela foi constituída de 12 plantas, sendo avaliadas as 10 plantas centrais. Realizou-se semanalmente após a $7^{\mathrm{a}}$ semana do transplantio, a avaliação da severidade nas folhas inferiores, medianas e superiores da planta foi feita com auxílio da escala diagramática proposta por Mello et al. (20). A severidade da doença ao longo do ciclo foi integralizada e calculada a área abaixo da curva de progresso da doença (AACPD), através da fórmula: $\mathrm{AACPD}=\sum[(y 1+y 2) / 2]^{*}(t 2-t 1)$, onde $y 1$ e $y 2$ refere-se a duas avaliações sucessivas da intensidade da doença realizadas nos tempos $t 1$ e $t 2$, respectivamente.

Avaliou-se a AACPD, a produtividade (Kg.ha- ${ }^{1}$ ) comercial, extra AA (>150 gramas) e extra A (100-150 gramas), a incidência de frutos com mancha bacteriana e a taxa de infecção aparente proposta por Vanderplank (29). Os dados das variáveis estudadas foram submetidas ao teste de normalidade e homogeneidade da variância e após à análise de variância (teste F). Havendo significância estatística $(p \leq 0,05)$ as médias foram comparadas entre si pelo teste de Tukey a 5\%.

\section{RESULTADOS E DISCUSSÃO}

Para os sistemas de previsão propostos no ciclo de 2006/2007, podese constatar que no sistema de previsão SE 0,05 houve um aumento de $50 \%$ no número de pulverização, quando comparado à pulverização a cada cinco dias, e de $111,7 \%$ na comparação com pulverização a cada sete dias (Tabela 1). No sistema SE 0,15 houve uma redução de 29,1\% no número de pulverizações, quando comparado a cada cinco dias e igualou-se a pulverização a cada sete dias (Tabela 1). Já no sistema SE 0,25 constatou-se uma redução de $118,18 \%$ e $54,54 \%$ em relação a pulverização a cada cinco e sete dias respectivamente (Tabela 1).

No ciclo 2007/2008, quando se comparam os sistemas SE 0,15 e SE 0,10 com duas pulverizações semanais verificou-se respectivamente uma redução de $65 \%$ e $50 \%$ respectivamente no número de pulverizações. No Sistema SE 0,05 teve-se uma redução de seis pulverizações em relação ao sistema convencional (Tabela 1). No ciclo $2009 / 2010$ houve uma redução de $48 \%$ para SE 0,10 e de $56 \%$ 
Tabela 1. Número de pulverizações, área abaixo da curva de progresso da doença (AACPD), produtividade (Kg.ha $\left.{ }^{-1}\right)$ e porcentagem de frutos com sintomas da mancha bacteriana do tomateiro (Xanthomonas spp.) resultantes de quatro sistemas de previsão ou controle convencional com pulverizações semanais regulares

\begin{tabular}{|c|c|c|c|c|c|c|c|c|c|c|c|c|c|}
\hline \multirow[b]{2}{*}{ Tratamentos } & \multirow{2}{*}{\multicolumn{3}{|c|}{ Número de pulverizações }} & \multirow{2}{*}{\multicolumn{4}{|c|}{ AACPD }} & \multicolumn{6}{|c|}{ Frutos comerciais } \\
\hline & & & & & & & & & Kg.ha $^{-1}$ & & $\%$ de fr & itos com $s$ & intomas \\
\hline SE 0,05 & 36 & 28 & - & 936,8 & $\mathrm{c}$ & $314,8 \mathrm{~ns}$ & - & $77.8 \mathrm{~ns}$ & $84.9 \mathrm{~ns}$ & - & $5,9 \mathrm{~ns}$ & $3,3 \mathrm{~ns}$ & - \\
\hline SE 0,15 & 17 & 12 & 11 & 1114,9 & $\mathrm{bc}$ & 408,7 & 270,7 & 75.7 & 84.5 & 58.2 & 6,3 & 3,7 & 1,6 \\
\hline SE 0,25 & 11 & - & - & 1205,7 & $\mathrm{~b}$ & - & - & 76.9 & - & - & 6,5 & - & \\
\hline $\begin{array}{l}\text { Convencional } \\
\text { ( } 5 \text { dias })\end{array}$ & 24 & - & - & 1337,1 & $a b$ & - & - & 77.6 & - & - & 5,8 & - & - \\
\hline $\begin{array}{l}\text { Convencional } \\
\text { ( } 7 \text { dias) }\end{array}$ & 17 & - & - & 1500,8 & a & - & - & 79.0 & - & - & 6,6 & - & - \\
\hline $\begin{array}{l}\text { Convencional } \\
\text { ( } 2 \text { vezes/semana) }\end{array}$ & - & 34 & 25 & - & & 469,7 & 236,3 & - & 82 & 67,0 & - & 5,6 & 1,5 \\
\hline Teste F & & & & 12,4 & & 1,8 & 0,2 & 0,1 & 0,03 & 0,6 & 1,7 & 0,45 & 0,08 \\
\hline CV $(\%)$ & & & & 12,2 & & 35,1 & 21,4 & 12,5 & 11,3 & 22,3 & 16,1 & 62,7 & 54,7 \\
\hline
\end{tabular}

Médias seguidas de mesma letra não diferem entre si pelo teste de Tukey a 5\%; ns: não significativo pelo teste $\mathrm{F}(P \leq 0,05)$; SE - Severidade estimada (\% de severidade em folhas/100); - : não avaliado; CV(\%): Coeficiente de variação.

para SE 0,15 se comparados a pulverização de duas vezes semanais (Tabela 1). Estudo realizado por Jardine \& Stephens (7) utilizando um sistema para a previsão de Pseudomonas syringae pv. tomato, constataram uma redução de até $25 \%$ no número de aplicações para a pinta bacteriana do tomateiro.

Na comparação da AACPD calculada para os dados do ciclo 2006/07, o sistema de previsão com SE 0,15 resultou em uma redução de $25,71 \%$ dessa variável, significativa estatisticamente, em relação às pulverizações realizadas a cada sete dias, e ambos os tratamentos apresentaram o mesmo número total de pulverizações (dezessete) (Tabela 1). O sistema de previsão com SE 0,15 não diferiu dos sistemas de previsão com SE 0,05 e SE 0,25 quanto à AACPD, mas apresentou um número intermediário de pulverizações ( 17 vs. 36 para SE 0,05 e 11 para SE 0,25$)$. Os sistemas de previsão com SE 0,15 e SE 0,25 não diferiram estatisticamente quanto a AACPD do sistema convencional de controle com pulverizações a cada cinco dias (Tabela 1). Nos ciclos 2007/08 e 2009/10 na variável AACPD não houve diferença significativa entre os sistemas de previsão em comparação com o sistema convencional de pulverização (Tabela 1).

Não houve diferença significativa entre os tratamentos para a produtividade $\left(\mathrm{Kg} \cdot \mathrm{ha}^{-1}\right)$ nos três ciclos de avaliação (Tabela 1). Para a porcentagem de frutos com sintomas não foram encontradas diferenças significativas nos três ciclos avaliados e analisando o ciclo de maior severidade da doença (2006/07), a diferença entre o sistema de previsão SE 0,05 e o sistema convencional a cada sete dias foi de $11,61 \%$. No ciclo 2007/2008 teve uma diferença de $69,7 \%$ entre o sistema SE 0,05 e convencional com duas pulverizações semanais.

Em 2006/2007, a severidade da doença foi maior no sistema convencional de controle com pulverização a cada 5 e 7 dias (Figura 1A), porém a taxa de infecção aparente não foi significativa quando comparou-se o sistema convencional com os sistemas de previsão (Tabela 2). No sistema de previsão SE 0,15 a severidade atingiu $44,6 \%$ na $10^{\text {a }}$ semana após o transplantio, enquanto que no sistema convencional a cada 5 e 7 dias apresentou respectivamente $49,9 \%$ e $56,3 \%$ de severidade. Porém quando se avalia a severidade final nesse ciclo, SE 025 não diferiu dos sistemas de controle convencional a cada 5 ou 7 dias; SE 015 ficou estatisticamente semelhante entre o sistema SE 0,05 e SE 0,25. Quanto a Figura 1A, os três sistemas de previsão

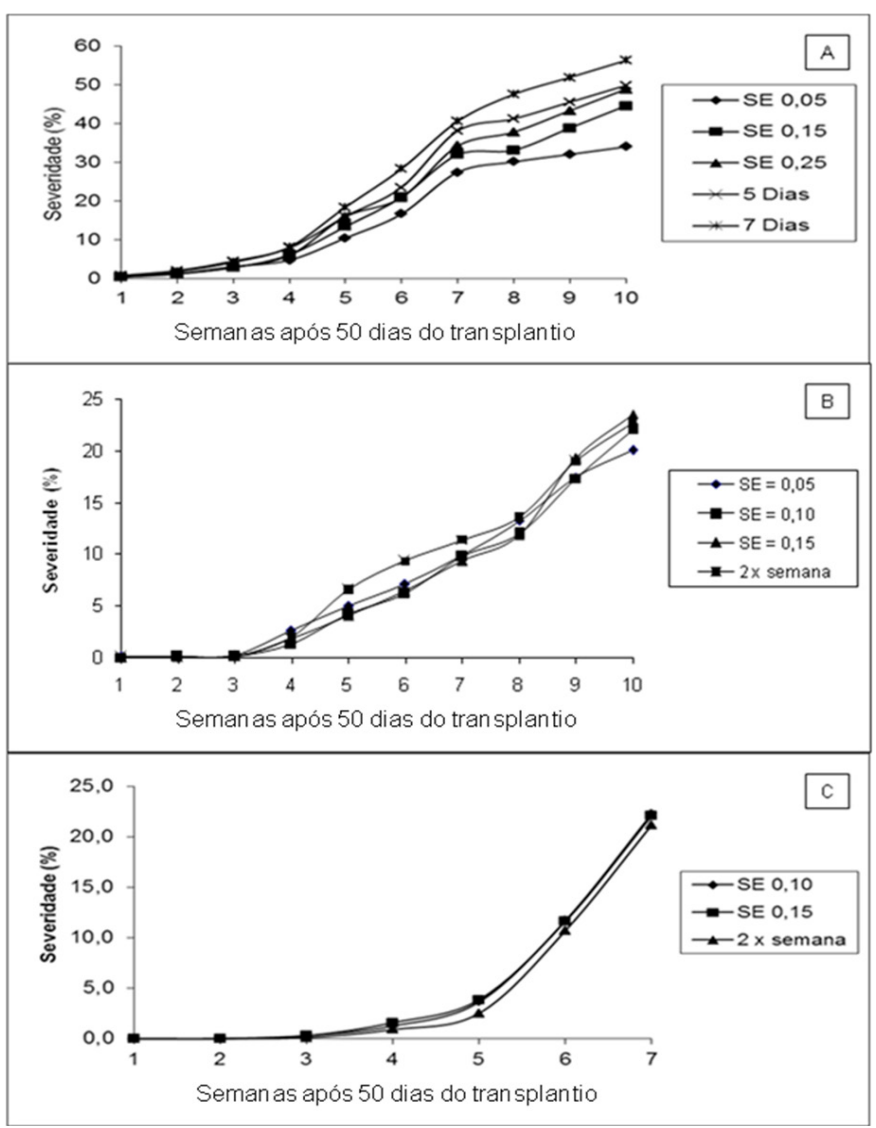

Figura 1. Curvas de progresso da severidade da mancha bacteriana do tomateiro (Xanthomonas spp.) em folhas (\%) resultantes de quatro sistemas de previsão ou controle convencional com pulverizações semanais regulares. Ciclo de cultivo 2006/07 (A); 2007/08 (B); 2009/10 (C).

resultaram em menores severidades finais que as pulverizações a cada 5 e 7 dias.

No ciclo 2007/2008 os valores percentuais de severidade final e taxa de infecção aparente não foram significativos pelo teste $\mathrm{F}$ 5\% (Tabela 2) e as curvas de progresso do sistema de previsão e convencional 
Tabela 2. Severidade final em folhas (\%) e taxas de infecção aparente ( $r$ ) da mancha bacteriana do tomateiro (Xanthomonas spp.) resultantes de quatro sistemas de previsão ou controle convencional com pulverizações semanais regulares

\begin{tabular}{|c|c|c|c|c|c|c|c|c|}
\hline \multirow[t]{2}{*}{ Tratamentos } & \multicolumn{5}{|c|}{ Severidade final (\%) em folhas } & \multicolumn{3}{|c|}{$r$} \\
\hline & & 06/07 & $2007 / 08$ & & & 2006/07 & $2007 / 08$ & $2009 / 10$ \\
\hline SE 0,05 & 34,0 & $\mathrm{c}$ & $20,0 \mathrm{~ns}$ & - & & $0,08 \mathrm{~ns}$ & $0,07 \mathrm{~ns}$ & - \\
\hline SE 0,15 & 44,6 & $\mathrm{~b}$ & 23,5 & 22,3 & $a b$ & 0,09 & 0,08 & 0,09 \\
\hline SE 0,25 & 48,9 & $a b$ & - & - & & 0,08 & - & - \\
\hline Convencional (5 dias) & 49,9 & $a b$ & - & - & & 0,07 & - & - \\
\hline Teste F & 13,8 & & 0,2 & 6,79 & & 0,6 & 2,1 & 1,1 \\
\hline $\mathrm{CV}(\%)$ & 11,6 & & 31,0 & 9,71 & & 24,6 & 14,1 & 22,7 \\
\hline
\end{tabular}

Médias seguidas de mesma letra não diferem entre si pelo teste de Tukey a $5 \%$; ns: não significativo pelo teste $\mathrm{F}(P \leq 0,05)$; - : não avaliado; $\mathrm{CV}(\%)$ : Coeficiente de variação.

aumentaram sucessivamente ao longo do tempo (Figura 1B). No ciclo 2009/10 as curvas de progresso entre os sistemas de previsão SE 0,10 e 0,15 e o convencional ficaram próximas (Figura $1 \mathrm{C}$ ), sendo não significativa a taxa de infecção aparente (Tabela 2), porém, o valor de severidade final de SE 0,15 não diferenciou estatisticamente de SE 0,10 e o sistema convencional de controle com pulverização feita duas vezes por semana (Tabela 2 ).

Teng (27) afirma que o rigor da avaliação não deve ser exagerado, uma vez que o sistema é uma aproximação da realidade e durante o processo de validação, se necessário, pode se ter um espaço entre o que é estimado e o real para aprimoramento contínuo do sistema (6). O modelo proposto permitiu demonstrar que é possível manejar a doença, já que a validação do modelo tem por objetivo determinar se o comportamento do sistema real é coerente com o modelo $(2,3,10)$.

A mancha bacteriana do tomateiro é uma das principais preocupações fitossanitárias dos produtores de tomate da Região do Alto Vale do Rio do Peixe (15). Considerando o aspecto econômico para o produtor, no sistema de previsão há uma redução no custo operacional, em decorrência da diminuição de até $65 \%$ no número de pulverizações e consequentemente menor exposição de quem realiza a pulverização ao agrotóxico. Quanto ao meio ambiente poderá haver uma diminuição significativa do impacto que o agrotóxico causa no ecossistema.

Em três ciclos de cultivo, com o uso do sistema de previsão representado por SE $=0,0001538 *\left\{\left[(x-8)^{2,4855647} *\left((32-x)^{0,7091962}\right)\right\}\right.$ * $\left\{\left[0,64289 /\left(1+21,26122 * \exp \left(-0,12435^{*} y\right)\right\}\right.\right.$, com nível de 0,15 demonstrou-se que foi possível à redução do número de pulverizações quando comparado ao sistema convencional para o controle mancha bacteriana do tomateiro causada por Xanthomonas spp. sem perda de produtividade.

\section{REFERÊNCIAS BIBLIOGRÁFICAS}

1. Barreto, M.; Vale, F.X.R.; Paul, P.A.; Scaloppi, E.A.G.; Andrade, D.F.A.A. Sistemas de previsão e estação de aviso. In: Vale, F. X. R.; Jesus Junior, W. C.; Zambolim, L (Ed.). Epidemiologia aplicada ao manejo de doenças de plantas. Belo Horizonte: Perffil, 2004. cap.6, p.243-266.

2. Bergamim Filho, A.; Amorim, L. Doenças de plantas tropicais: epidemiologia e controle econômico. São Paulo: Ceres, 1996. 299p.

3. Bergamim Filho, A.; Amorim, L. Sistemas de previsão e avisos. In: Bergamim Filho, A.; Kimati, H.; Amorim, L. (Ed.). Manual de fitopatologia. 3. ed. São Paulo: Ceres, 1995. v. 1, cap. 31, p.627-646.

4. Costa, J.R.; Araújo, E.R.; Becker, W.F.; Ferreira, M.A.S.V.; Quezado-Duval, A.M. Ocorrência e caracterização do complexo de espécies causadoras da mancha bacteriana do tomateiro no Alto Vale do Rio do Peixe, SC. Tropical
Plant Pathology, Brasília, DF, v.37, n.2, p.149-154, 2012.

5. Epagri. Normas técnicas para o tomateiro tutorado na região do Alto Vale do Rio do Peixe. Florianópolis, 1997. 60 p. (Sistema de Produção, 27).

6. Fernandes, J.M.C.; Maffia, L.A. Simulação de epidemias. Revisão Anual de Patologia de Plantas, Passo Fundo, v.2, p.293-334, 1994.

7. Jardine, D.J.; Stephens, C.T.A. Predictive system for timing Chemical applications to control Pseudomonas syringae pv. tomato, causal agent of bacterial speck. Phytopathology, St. Paul, v.77, n.6, p.823-827, 1987.

8. Jesus Junior, W.C.; Pozza, E.A.; Vale, F.X.R.; Anguilera, G.M. Análise temporal de epidemias. In: Vale, F. X. R.; Jesus Junior, W. C.; Zambolim, L. (Ed.). Epidemiologia aplicada ao manejo de doenças de plantas. Belo Horizonte: Perffil, 2004. cap.4, p.127-191.

9. Jones, A.L.; Lacy, G.H.; Bouzar, H.; Stall, R.E.; Schaad, N.W. Reclassification of the Xanthomonads associated with bacterial spot disease of tomato pepper. Systematic and Applied Microbiology, Stuttgart, v.27, n.6, p.755-762, 2004.

10. Kranz, J.; Hau, B. Systems analysis in epidemiology. Annual Review of Phytopathology, Palo Alto, v.18, n.1, p.67-83, 1980.

11. Krause, R.A.; Massie, L.B. Predictive systems: modern approaches to disease control. Annual Review of Phytopathology, Palo Alto, v.13, n.1, p.31-47, 1975.

12. Lopes, C.A.; Quezado-Duval, M.A. Doenças bacterianas. In: Lopes, C.A.; Àvila, A.C. Doenças do tomateiro. Brasília, DF: Embrapa-CNPH, 2005. p.62-64.

13. Lopes, C.A.; Santos, J.R.M. Doenças do tomateiro. Brasília, DF: Embrapa-CNPH, 1994. p.51-58.

14. Malavolta Junior, V.A. Doenças bacterianas em tomateiro: etiologia e controle. Campinas: IAC, 2008. Disponível em: <www.portaluniagro.com. br/realizações/doebacter.pdf $>$. Acesso em: 12 ago. 2007.

15. Marcuzzo, L.L. Epidemiologia e previsão da mancha bacteriana (Xanthomonas spp.) do tomateiro. 2008. 68 f. Tese (Doutorado em Agronomia/Fitopatologia) - Universidade de Passo Fundo, Passo Fundo.

16. Marcuzzo, L.L.; Fernandes, J.M.C.; Becker, W.F. Influência da temperatura e da duração do molhamento foliar na severidade da mancha bacteriana do tomateiro. Summa Phytopathologica, Botucatu, v.35, n.3, p.229-230, 2009a.

17. Marcuzzo, L.L.; Becker, W.F.; Fernandes, J.M.C. Alguns aspectos epidemiológicos da mancha bacteriana (Xanthomonas spp.) do tomateiro na região de Caçador/SC. Summa Phytopathologica, Botucatu, v.35, n.2, p.132-135, 2009b.

18. Maringoni, A.C.; Kurozawa, C.; Barbosa, V.; Silva Neto, J.M. Controle químico da mancha bacteriana (Xanthomonas campestris pv. vesicatoria (DOIDGE) DYE) do tomateiro (Lycopersicon esculentum MILL.). Summa Phytopathologica, Piracicaba, v.12, n.1, p.92-101, 1986.

19. Mello, S.M.C.; Takatsu, A.; Lopes, C.A. Escala diagramática para avaliação da mancha-bacteriana do tomateiro. Fitopatologia Brasileira, Brasília, DF, v.22, n.3, p.447-448, 1997.

20. Mizubuti, E.S.G. Sistema de previsão de doenças de plantas: uma ferramenta útil? In: Zambolim, L. (Ed). $1^{\circ}$ Encontro de manejo integrado de doença e pragas. Viçosa: Universidade Federal de Viçosa, 1999. p.42-46.

21. Pandolfo, C.; Braga, H.J.; Silva Júnior V.P.; Massignam, A.M.; Pereira, 
E.S.; Thomé, U.M.R. Atlas climatológico do Estado de Santa Catarina. Florianópolis: Epagri (1 CD-ROM), 2002.

01. Quezado-Duval, A. M. Diversidade de Xanthomonas spp. associada a mancha bacteriana em tomateiro para processamento industrial. 2003. 111f. Tese (Doutorado em Fitopatologia) - Escola Superior de Agricultura Luiz de Queiroz, Universidade de São Paulo, Piracicaba.

22. Reis, E.M. Previsão de doenças de plantas. Passo Fundo: Universidade de Passo Fundo, 2004. 316p.

23. Romeiro, R.S.; Vieira Junior, J.R. Importância de antibióticos para o controle de fitopatógenos e para outras finalidades em fitopatologia. Summa Phytopathologica, Botucatu, v.31, supl., p.132-135, 2005. (Resumo).

24. Síntese Anual da Agricultura de Santa Catarina 2011-2012. Florif anópolis: Epagri/Cepa. Disponível em: < http://www.epagri.sc.gov. br/?page_id=3210 $>$. Acesso em: 4 jul. 2013.

25. Sutton, J.C. Predictive value of weather variables in the epidemiology and management of foliar disease. Fitopatologia Brasileira, Brasília, DF, v.13, n. 4 , p. 305-312, 1988 .

26. Teng, P.S.A. Comparison of simulation approaches to epidemic modeling. Annual Review of Phytopathology, Palo Alto, v.23, p.351-379, 1985.

27. Vale, F.X.R.; Zambolim, L. Influência da temperatura e da umidade nas epidemias de doenças de plantas. Revisão Anual de Patologia de Plantas, Passo Fundo, v.4, p.149-207, 1996.

28. Vanderplank, J.E. Plant disease: epidemics ant control. New York: Academic Press, 1963. 349p. 